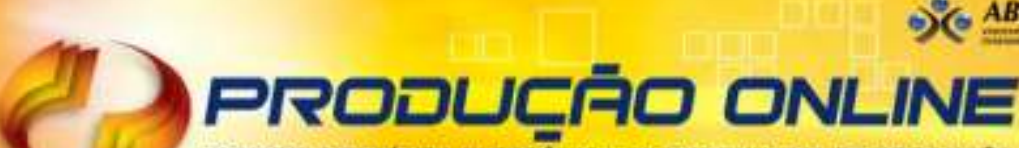 \\ REVISTA CIENTIFICA ELETRÓNICA DE ENGENHARIA DE PRODUCATO \\ ISSN 1676-1901
}

\section{A COORDENAÇÃO CIVIL-MILITAR NA LOGÍSTICA HUMANITÁRIA E O PAPEL DAS FORÇAS ARMADAS BRASILEIRAS NO GERENCIAMENTO DE DESASTRES}

\section{CIVIL-MILITARY COORDINATION IN HUMANITARIAN LOGISTICS AND THE ROLE OF THE ARMED FORCES IN BRAZILIAN DISASTER MANAGEMENT}

\author{
Paulo Ricardo Sousa da Rosa* e-mail: pauloricardosousa@yahoo.com.br \\ Renata Albergaria de Mello Bandeira* e-mail: re.albergaria@gmail.com \\ *Instituto Militar de Engenharia (IME), Rio de Janeiro, RJ
}

Resumo: Este trabalho aborda as normas e conceitos internacionais utilizados na coordenação civilmilitar no contexto da logística humanitária, apresentando os tipos de emprego dos meios militares nas diferentes respostas humanitárias; destacando a atuação das Forças Armadas nas operações de resposta a desastres encontrados na literatura acadêmica e analisando os principais desafios e limitações desta coordenação. Também são analisados no artigo as capacidades operacionais e o papel dos militares em operações de resposta a desastres, discutindo-se a atuação das Forças Armadas brasileiras na gestão de desastres, com seus desafios e limitações de coordenação no país, finalizando com recomendações para uma maior eficiência da ação militar na logística humanitária em operações de resposta a desastres.

Palavras-chaves: Coordenação civil-militar. Gestão de desastres. Logística humanitária. Desafios e limitações.

\begin{abstract}
This work deals with international norms and concepts used in civil-military coordination in the context of humanitarian logistics, presenting the types of employment of military assets in various humanitarian responses. It highlights the role of Armed Forces in disaster response operations as for the academic literature and analyzes the main challenges and limitations of this coordination. The operational capacity and role of the military in disaster response operations are also analyzed, discussing the performance of the Brazilian Armed Forces in disaster management, as well as coordination challenges and limitations in the country. The paper wraps up with recommendations for efficient military action in humanitarian logistics in disaster response operations.
\end{abstract}

Keywords: Civil-military coordination. Disaster management. Humanitarian logistics. Challenges and limitations.

\section{INTRODUÇÃO}

A população mundial está cada vez mais propensa a sofrer a ação de eventos naturais devido ao crescimento urbano desordenado e às alterações climáticas (ONU, 2011). Segundo NATARAJARATHINAM, CAPAR e NARAYANAN (2009), desastres são eventos súbitos e inesperados ou lentos, caracterizados por atingir uma determinada região causando danos econômicos, sociais e ambientais e podendo resultar em mortos e feridos. Na última década, o Brasil tem sofrido, em média, seis desastres por ano (ONU, 2011) e, em 2008, foi o décimo terceiro país mais afetado por desastres naturais, tendo aproximadamente dois milhões de vítimas afetadas 
principalmente por enchentes e deslizamentos (LIMA, MEDEIROS e GONÇALVES, 2014).

Um ponto comum observado em desastres recentes tem sido o envolvimento significativo de militares (WEEKS, 2007 e PROJECT, 2011). A participação militar em operações humanitárias, tanto em casos de conflito armado ou em resposta a desastres naturais, não é um fenômeno novo. As forças militares nacionais e internacionais têm desempenhado um papel importante na prestação de apoio (APTE, 2009; HEASLIP et al., 2010 e HEASLIP et al., 2012).Os militares possuem capacidades únicas que podem ser aplicadas em operações humanitárias (PUGH, 1998), além da estrutura de comando e controle, fundamental em caso de situações caóticas - como guerras e desastres (APTE, 2009). A atuação dos atores militares na ação humanitária tem uma longa história, como ilustrado pela Crise da Abissínia (1935-1936) e o transporte aéreo de Berlim (1948).

Em teoria, o uso de ativos de defesa militar e civil (Military and Civil Defense Assets - MCDA) em emergências complexas e desastres naturais é limitado por quadros políticos internacionais para situações de "último recurso". De acordo com as Diretrizes civil - militar de referência para emergências complexas (OCHA, 2008a) e as Diretrizes de uso de recursos militares e de defesa civil estrangeiro para operações de socorro em casos de desastres - Diretrizes de Oslo (OCHA, 2007), o princípio do "último recurso" requer que as forças armadas assegurem o suporte nas operações humanitárias somente de acordo com quatro critérios principais: (i) CAPACIDADE ÚNICA - não existir nenhum recurso civil alternativo adequado para a situação; (ii) OPORTUNIDADE - a urgência da tarefa demandada requer uma ação imediata; (iii) FOCO HUMANITÁRIO - o controle civil sobre a utilização dos meios militares e; (iv) TEMPO LIMITADO - a utilização de meios militares para apoiar atividades humanitárias é claramente limitado no tempo e escala.No entanto, na realidade, o correto entendimento deste princípio tem sido um problema, e considerações políticas têm colocado pressão sobre os militares para implantar seus ativos, e sobre os atores humanitários para aceitá-los, mesmo que a sua utilização possa não estar em conformidade com o princípio do último recurso (METCALFE; HAYSOM; GORDON, 2012).

Este contexto acaba por gerar maior interação entre os militares e as agências de ajuda humanitária para desempenho das operações humanitárias (BYMAN, 2010), de modo que a coordenação entre estas duas comunidades se torna necessária para melhorar a eficiência na cadeia de suprimentos humanitários (APTE, 2009). No entanto, de acordo com Metcalfeet al. (2012), os debates propostos sobre a coordenação civil-militar na logística humanitária tendem a se concentrar em questões conceituais, preocupando-se principalmente com princípios de emprego, não existindo uma análise e debate sobre como a relação funciona a um nível prático, e o mais importante, como os resultados desta relação impactam as populações que necessitam de proteção e assistência.

Desta forma, o presente trabalho aborda as normas e conceitos internacionais utilizados na coordenação civil-militar no contexto da logística humanitária, apresentando os tipos de emprego dos meios militares nas diferentes respostas Revista Produção Online, Florianópolis, SC, v. 16, n. 3, p. 895-915, jul./set. 2016. 
humanitárias; destacando a atuação das FA nas operações de resposta a desastres encontrados na literatura acadêmica e analisando os principais desafios e limitações desta coordenação. Também são analisados no artigo as capacidades operacionais e o papel dos militares em operações de resposta a desastres, discutindo-se a atuação das Forças Armadas brasileiras na gestão de desastres, com seus desafios e limitações de coordenação no país, finalizando com recomendações para uma maior eficiência da ação militar na logística humanitária em operações de resposta a desastres.

\section{NORMAS E CONCEITOS UTILIZADOS NA COORDENAÇÃO CIVIL-MILITAR EM LOGÍSTICA HUMANITÁRIA}

O diálogo é essencial para a interação entre atores civis e militares em situações de emergência humanitária, necessário para proteger e promover os princípios humanitários, evitar a competição, minimizar inconsistências e, quando apropriado, buscar objetivos comuns (OCHA, 2008b). O espectro de interação entre atores civis e militares vai desde a coexistência até a cooperação, conforme representado na Figura 1.

Figura 1: A amplitude do relacionamento civil - militar.

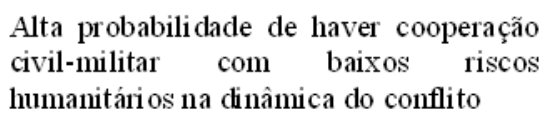

Baixa probabilidade de haver cooperação civil-militar com altos riscos humanitários na dinâmica do conflito

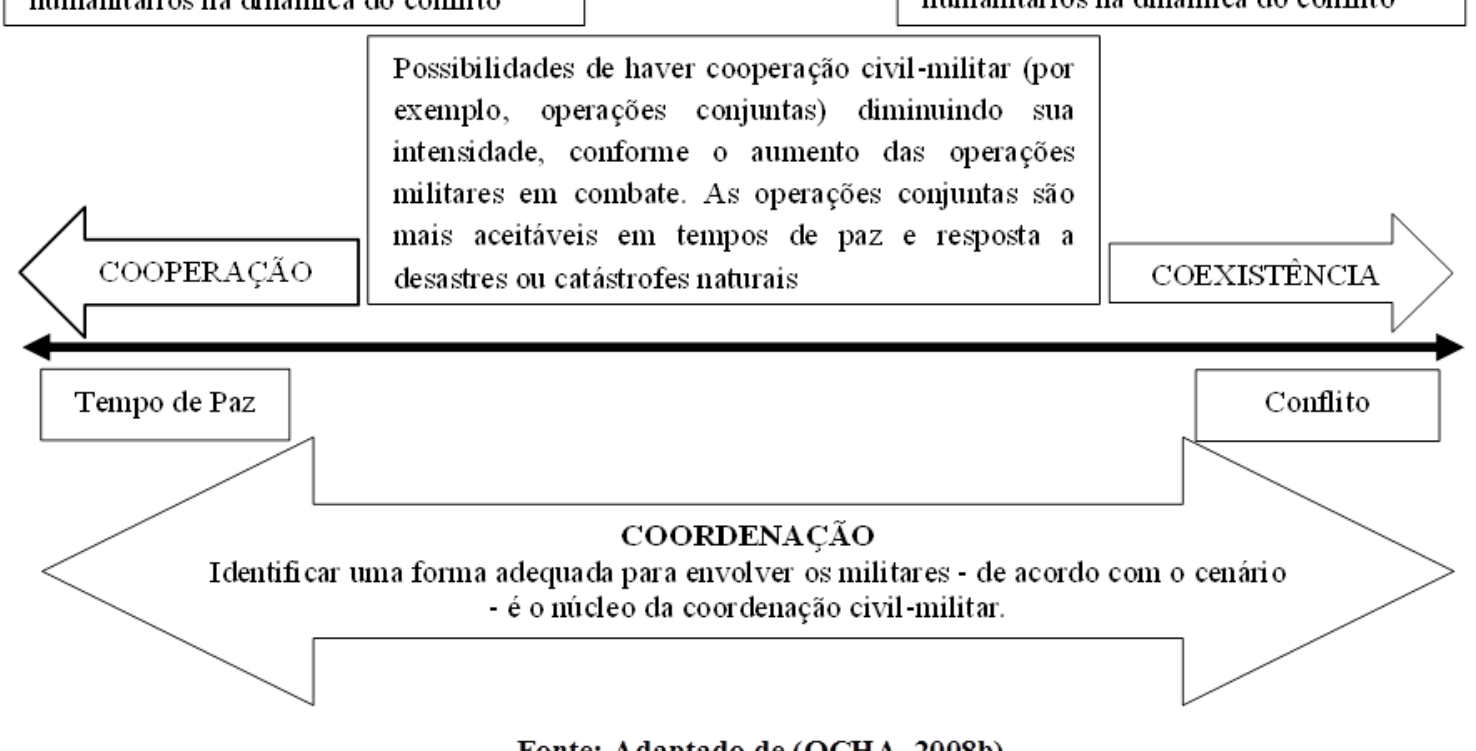

Fonte: Adaptado de (OCHA, 2008b)

É importante destacar que os termos e conceitos existentes: (i) RELAÇÕES CIVIS - MILITARES (Civil-Military Relations), (ii) COORDENAÇÃO CIVIL-MILITAR (CivilMilitary Coordination - CMCoord) e(iii) COOPERAÇÃO CIVIL-MILITAR (Civil-Military Cooperation - CIMIC); são muitas vezes confundidos na literatura(METCALFE, HAYSOM e GORDON, 2012), de modo que, na Tabela 1, são resumidos os principais 
termos utilizados, seus conceitos e interpretação na coordenação civil-militar, bem como as organizações internacionais que tratam respectivamente dos assuntos.

Tabela 1: Diferentes termos e conceitos utilizados na coord en ação civil-militar.

\begin{tabular}{l|l|l}
\multicolumn{1}{c|}{ TERMO } & \multicolumn{1}{c|}{ CONCEITO } & \multicolumn{1}{c}{$\begin{array}{c}\text { ORGANIZAÇÃO } \\
\text { INTERNACIONAL }\end{array}$} \\
\hline $\begin{array}{l}\text { Relações Civis - } \\
\text { Militares }\end{array}$ & $\begin{array}{l}\text { Termo amplo, genérico, usado para objetivos diversos, } \\
\text { principalmente políticos. Atores Civis X Atores Militares }\end{array}$ & ONU e UE \\
\hline $\begin{array}{l}\text { Coordenação Civil- } \\
\text { Militar - CMCoord }\end{array}$ & $\begin{array}{l}\text { Termo específico, criado exclusivamente para propósitos } \\
\text { humanitários. Organizações Humanitárias X Atores Militares }\end{array}$ & OCHA e IASC \\
\hline $\begin{array}{l}\text { Cooperação Civil- } \\
\text { Militar - CIMIC }\end{array}$ & $\begin{array}{l}\text { Conceito exclusivo para Militares. Operações Militares } \\
\text { envolvendo participação de civis. Apoio ao Comandante Militar } \\
\text { em certas operações. Atores Militares X Atores Civis }\end{array}$ & OTAN \\
\hline CIMIC da ONU & $\begin{array}{l}\text { Foco no mandato (objetivo) da missão da ONU. Leva em } \\
\text { consideração os aspectos humanitários. Componente Militar da } \\
\text { Missão X Componente Civil da Missão }\end{array}$ & DPKO \\
\hline CIMIC da UE & $\begin{array}{l}\text { Entendimento semelhante ao CIMIC ONU. As atividades } \\
\text { militares devem complementar e apoiar as organizações } \\
\text { humanitárias. Parlamento Europeu } \\
\text { Fonte: Adaptado de METCALFE, HAYSOM e GORDON (2012) }\end{array}$
\end{tabular}

A crescente complexidade das esferas políticas e operacionais e o aumento do número de situações em que atores humanitários e forças militares entraram em proximidade física um com o outro resultaram numa proliferação de orientações e normativos para regular a interação civil-militar em questões humanitárias.No entanto, METCALFE et al. (2012)salientam que tem sido pouca esta adesão a tais normas. Verifica-se também que as orientações existentes não atendem às demandas dos ambientes operacionais atuais, e em particular, existem lacunas relativas à coordenação das forças armadas nacionais e internacionais com empresas militares privadas; além da falta de normatização e orientação na coordenação nos casos de combinação de conflito armado e desastre natural (como foi, por exemplo, no terremoto do Haiti em 2010)(NMCG et al., 2011;OCHA, 2011 e IASC, 2011).

As duas principais fontes não vinculativas de orientação e política de coordenação civil-militar humanitária continuam sendo as Diretrizes para Emergências Complexas (OCHA, 2008a), coletânea composta de quatro volumes, utilizada no caso de conflitos; e as Diretrizes de Oslo (OCHA, 2007), utilizada no caso de desastres ou catástrofes naturais, conforme apresentado na Tabela 2. Além disso, tanto os militares como a comunidade humanitária desenvolveram orientações adicionais ou suplementares sobre esta coordenação civil-militar (METCALFE et al. 2012).

Segundo Bessler e Seki (2006), o documento de referência elaborado pelo Comitê Permanente Inter Agências (Inter-Agency Standing Committee - IASC), chamado de relações civil-militar em situações de emergência complexas (IASC, 2004), é visto como uma ferramenta genérica, criada para facilitar a formulação de diretrizes específicas para cada país. Embora o documento do IASC reconheça o papel dos militares e atores civis na resposta humanitária, o normativo estabelece uma diferença entre "assistência humanitária" realizada por civis e "prestação de ajuda ou socorro" realizada pelo militares. A diretriz do IASC reconhece que, em circunstâncias em que as organizações civis humanitárias são incapazes de operar, ou onde os 
militares estão ocupando o poder ou governo do país e assumindo as responsabilidades perante a população civil, o apoio militar para a ajuda, socorro e assistência são necessários(UNCH, 2006).

Tabela 2: Principais normativos in ternacionais na coordenação civil-militar

\begin{tabular}{|c|c|}
\hline Normativos & Assunto abordado \\
\hline $\begin{array}{l}\text { Diretrizes de Oslo } \\
\qquad(2007)\end{array}$ & $\begin{array}{l}\text { Diretrizes para uso de recursos militares e de defesa civil estrangeiros em } \\
\text { catástrofes ou desastres naturais. }\end{array}$ \\
\hline \multirow{4}{*}{$\begin{array}{l}\text { Diretrizes das relações civil- } \\
\text { militar para situações de } \\
\text { emergência complexas } \\
\text { (2008) } \\
\text { Coletânea composta de quatro } \\
\text { documentos. }\end{array}$} & $\begin{array}{l}\text { Relações civil-militar em situações de emergência complexas, elaborado } \\
\text { pelo Inter-Agency Standing Committee (IASC) }\end{array}$ \\
\hline & $\begin{array}{l}\text { Diretrizes de utilização de recursos militares e de defesa civil em apoio às } \\
\text { atividades humanitárias das nações unidas em situações de emergências } \\
\text { complexas - Diretrizes MCDA }\end{array}$ \\
\hline & Uso de escoltas militares armadas para comboios humanitários \\
\hline & $\begin{array}{l}\text { Manual de Campanha das Nações Unidas para coordenação civil-militar } \\
\text { Fonte: Elaborado pelos au tor es }\end{array}$ \\
\hline
\end{tabular}

Rana e Reber (2007)fizeram uma divisão dessas diversas orientações, agrupando-as em três grandes categorias:(i) orientações gerais em matéria de relações entre civis e militares (Diretrizes Gerais do IASC, Código de Conduta do Comitê Internacional da Cruz Vermelha e a Carta Humanitária do Projeto Esfera); (ii) orientações específicas sobre relações civis-militares em uma determinada emergência complexa ou conflito armado (Diretrizes específicas para o Iraque e o Afeganistão ou países que hospedam missões de paz) e; (iii) orientações em assuntos específicos das relações entre civis e militares (Orientações MCDA e utilização de militares em escoltas armadas para comboios humanitários).

Essas orientações reconhecem que a coordenação é necessária para evitar a duplicidade de funções, identificar as lacunas existentes e garantir a melhor utilização dos recursos disponíveis; garantindo a segurança das populações afetadas e dos agentes humanitários (SCHR, 2010 e OCHA, 2008a).Contudo, de acordo com Metcalfe, Haysom e Gordon (2012), existe pouca discussão se estas diretrizes e orientações específicas de cada país: (i) são elaboradas de forma correta, (ii) são cumpridas ou não, (iii) são divulgadas efetivamente, (iv) se existe falta de treinamento dos atores, (v) se existe falta de clareza nas orientações ou,(vi) outros fatores políticos.

\section{TIPOS DE APOIO OU EMPREGO DOS MEIOS MILITARES NAS RESPOSTAS HUMANITÁRIAS}

De acordo com os normativos internacionais apresentados na seção 2 e sumarizados na Tabela 2, é possível identificar as principais situações que os meios militares são utilizados na prestação do socorro ou ajuda humanitária, conforme subseções abaixo.

\subsection{Emprego de meios militares em conflitos}


Verifica-se nas últimas décadas a evolução dos mandatos de missões de paz "multidimensionais" da ONU, caracterizando-se por ações políticas, militares e civis para apoiar as transições da guerra para a paz, com características cada vez mais "abrangentes e complexas",(EIDE et al., 2005 e METCALFE et al. 2012). No entanto, segundo Harmer (2008), há uma contradição básica entre os objetivos políticos das missões de paz da ONU e os seus objetivos humanitários: é que,neste processo, não se faz distinção entre os atores humanitários, políticos e militares; deixando de lado as prioridades humanitárias em detrimento da política ou aos objetivos das missões de paz, colocando assim em risco os atores no espaço humanitário.

\subsection{Emprego de meios militares como segurança armada (escolta de comboios)}

As Diretrizes do IASC sobre escoltas armadas (OCHA, 2007)restringem a utilização dos meios militares para apoiar a segurança dos trabalhadores humanitários; entretanto, na prática, aderir a estes critérios se mostrou um grande problema (IASC, 2013).Em missões de paz, a tendência é recorrer automaticamente à utilização desta segurança armada por parte das agências humanitárias da ONU e seus parceiros, devido a investimentos insuficientes nas capacidades e recursos civis necessários para avaliar com precisão as ameaças à segurança(METCALFE et al.2011).

\subsection{Emprego de meios militares na assistência a refugiados ou proteção de civis}

$\mathrm{Na}$ literatura internacional, parece haver consenso sobre o conceito que a proteção de civis significa: mitigar ou reduzir as ameaças que estes enfrentam em conflitos armados ou outras situações de violência (O'CALLAGHAN e PANTULIANO, 2007). Nestas situações, tantos os militares como agentes humanitários reconhecem que cada um tem uma contribuição importante em relação a este assunto. No entanto, apesar de trabalharem coma mesma meta ou objetivo (ou seja, reduzir e mitigar as ameaças a civis), as táticas e estratégias dos militares e atores civis são bastante diferentes(LILLY, 2010 e HPG e ICRC, 2011).

\subsection{Emprego de meios militares em resposta a desastres}

Segundo METCALFE, HAYSOM e GORDON (2012), a utilização de militares em catástrofes serão um recurso recorrente, envolvendo tanto militares ocidentais como orientais. O Departamento de Defesa dos Estados Unidos tem declarado que esses empregos serão as principais missões militares no futuro (DOD, 2010).De fato, um ponto comum observado em desastres recentes tem sido o significativo envolvimento de militares (WEEKS, 2007; PROJECT, 2011 e ROSA et al. 2014).

No presente artigo, o foco será o emprego da logística militar em resposta a desastres. Desta forma, a seção a seguir apresenta as capacidades operacionais e o papel dos militares nas operações de resposta a catástrofes. 


\section{ATUAÇÃO DAS FORÇAS ARMADAS EM OPERAÇÕES DE RESPOSTA A DESASTRES}

Pettit e Beresford (2005) destacam as capacidades operacionais das Forças Armadas, que são essenciais em operações de resposta a desastres: (i) segurança; (ii) transporte e logística; (iii) construção e reparação; (iv) comando, controle e comunicações; (v) cuidados médicos; (vi) unidades especializadas; e (vii) preparação. A Tabela 3 detalha estas capacidades operacionais.

Tabela 3: Capacidades Operacionais das FA em resposta a desastres

\begin{tabular}{|c|l|}
\hline Segurança & $\begin{array}{l}\text { Estabelecimento de abrigos, proteção dos suprimentos, manutenção de uma presença } \\
\text { armada robusta para reduzir a ameaça de violência. }\end{array}$ \\
\hline $\begin{array}{c}\text { Transporte e } \\
\text { logística }\end{array}$ & $\begin{array}{l}\text { Capacidade rápida de transporte de pessoal e suprimentos, fornecimento contínuo de } \\
\text { equipamentos e materiais. }\end{array}$ \\
\hline $\begin{array}{c}\text { Construção e } \\
\text { reparação }\end{array}$ & $\begin{array}{l}\text { Construção ou reparação de infra-estruturas essenciais - estradas, portos, aeroportos, } \\
\text { ferrovias e instalações de armazenamento. }\end{array}$ \\
\hline $\begin{array}{c}\text { Comando, controle } \\
\text { e comunicações }\end{array}$ & $\begin{array}{l}\text { Sistemas de comunicações sofisticados, execução ágil de complexos planos de } \\
\text { contingência, planejamento central e capacidade de direção, organizacão básica e } \\
\text { estrutura de comunicações para organizações de ajuda humanitária. }\end{array}$ \\
\hline Cuidados médicos & $\begin{array}{l}\text { Equipes médicas implantáveis rapidamente, sistemas de evacuação, prevenção e } \\
\text { controle da doença, uso de unidades de purificação de água. }\end{array}$ \\
\hline $\begin{array}{c}\text { Unidades } \\
\text { especializadas }\end{array}$ & $\begin{array}{l}\text { Pessoal treinado para fazer a interface entre as populações civis e militares, } \\
\text { especialistas em transporte, negócios, direito, comunicação, saúde, policiamento. }\end{array}$ \\
\hline Preparação & $\begin{array}{l}\text { Formação conjunta de pessoal militar e civil em preparação para, por exemplo, } \\
\text { situações de desastre em massa }\end{array}$ \\
\hline Fonte: Adaptado de PETTIT e BERESFORD (2005)
\end{tabular}

Hanley (2010) aponta que, além destas capacidades específicas, destacadas por Pettit e Beresford (2005), outros fatores políticos também motivam o aumento da participação dos militares em operações de respostas a desastres internacionais. Contudo, Hanley (2010) e Lipner e Henley (2010) argumentam que o aumento do emprego militar estrangeiro ou internacional na gestão de desastres é necessário, porque cada vez mais pessoas serão afetadas pelos impactos dos desastres naturais, cuja frequência é cada vez maior. Este contexto acaba por exigir a cooperação entre militares e agências de ajuda humanitária para desempenho das operações de resposta a desastres (BYMAN, 2010).

Conforme previsto na Constituição de cada país, as FA destinam-se à defesa da pátria, à garantia dos poderes constitucionais e da lei e da ordem. Por isto, princípios comuns às ações humanitárias, como a imparcialidade e neutralidade, não podem ser implementados pelos militares. Desta forma, organizações não governamentais (ONGs) temem que, em longo prazo, a associação com militares ameace sua imagem imparcial e coloque o seu trabalho em risco (BYMAN, 2010). No entanto, muitos críticos consideram essa noção de neutralidade um tanto ingênua e equivocada (WEISS, 1997). Para Rietjenset al.(2009), os esforços humanitários são profundamente políticos, pois devem alterar o equilíbrio do poder em favor das vítimas. Collinson, Elhawary e Muggah (2010) consideram as agências humanitárias como agentes políticos operando em ambientes políticos complexos.

Segundo Project(2011), as ONGs ao trabalharem em conjunto com os militares em operações humanitárias devem evitar qualquer associação real ou percebida com Revista Produção Online, Florianópolis, SC, v. 16, n. 3, p. 895-915, jul./set. 2016. 
uma agenda política que possa comprometer a sua independência, credibilidade, segurança e acesso às populações afetadas.Em contrapartida, nas catástrofes, é difícil haver uma oposição política significativa ou manifestações contestando a presença de forças militares estrangeiras (RIETJENS, VOORDIJK e BOER, 2007; KOVÁCS e TATHAM, 2009 eHEASLIP et al., 2012).

De acordo com Burkle (2005), a comunidade humanitária espera que os militares proporcionem proteção às ONGs, não ajuda humanitária. No entanto, o autor destaca que a assistência humanitária pelas FA é essencial em situações em que a presença de agências humanitárias é inexistente ou insuficiente, ou quando o ambiente de segurança é proibitivo, impedindo o acesso. Entre os atores envolvidos em operações humanitárias, as unidades militares estão frequentemente entre os primeiros a entrar em cena na situação de desastre (WEEKS, 2007 e HEASLIP et al., 2010). Os ativos capazes de serem rapidamente e efetivamente implantados em resposta a desastres são, muitas vezes, detidos por militares: combustíveis, equipamentos para transportes e comunicações, equipamentos de engenharia e de construção, medicamentos e estoque de provisões, como alimentos e água(OLORUNTOBA, 2010).

De acordo com Davidson, Hayes e Landon (1996), as principais missões dos militares, em operações de resposta a desastres, são: estabelecer um ambiente seguro para organizações humanitárias trabalharem, fornecer transporte e comunicações. No entanto, na dura realidade de um desastre, as linhas entre os papéis dos militares e de organizações humanitárias têm sido, por vezes, turvas e difíceis (VAN WASSENHOVE, 2006). Assim, o escopo das ações militares neste tipo de operação tem variado, podendo se restringir a oferta de serviço de transporte de insumos de socorro e/ou de mão de obra para dentro da área do desastre até a participação ativa nos esforços de alívio de grande escala (THOMPSON, 2010). No entanto, deve-se considerar que o custo do emprego de militares em operações humanitárias é mais elevado (WEISS, 1997).

Ainda convém destacar que o tipo e a forma de prestação de ajuda humanitária vêm se tornando mais complexos ao longo das últimas décadas, refletindo diretamente sobre a operação e o envolvimento militar na assistência humanitária em relação aos suprimentos e suporte logístico prestados na ajuda (JAHRE, JENSEN e LISTOU, 2009). A resposta militar, após a solicitação do pedido para ajuda em um desastre natural, depende da:(i) escala e urgência do evento, (ii) do nível de preparação da tropa, (iii) das relações previamente estabelecidas entre o país afetado e aquele ao qual pertence as FA em ação, (iv) das forças auxiliares locais e política do país anfitrião; (v) da proximidade geográfica e (vi) se o país onde ocorreu o desastre tem a disponibilidade de meios militares para dar a assistência na área do desastre (RIETJENS, VOORDIJK e BOER, 2007; JAHRE, JENSEN e LISTOU, 2009 eHEASLIP et al., 2012).

Entretanto, a atuação militar em operações de resposta a desastres tem sido pouco abordada como tema de pesquisa no campo da logística humanitária. Heaslip e Barber (2014) realizaram uma revisão sistemática da literatura internacional com o objetivo de compreender os desafios da cooperação, coordenação e colaboração Revista Produção Online, Florianópolis, SC, v. 16, n. 3, p. 895-915, jul./set. 2016. 
entre civis e militares em cadeias de suprimento humanitárias, e identificaram 30 artigos que tratam do funcionamento e papeis de forças militares durante a ocorrência de um desastre. Os autores propõem uma classificação do envolvimento militar em operações de ajuda humanitária, enquadrando os artigos segundo esta proposta, tal como apresentado na Tabela 4.

Tabela 4: Publicações intern acionais focand o o envolvim ento militar em Logística Humanitária

\begin{tabular}{l|l}
\multicolumn{1}{c|}{ Tipo de Envolvim ento Militar } & \multicolumn{1}{c}{ Autores } \\
\hline Atividades em cadeias de suprimentos & $\begin{array}{l}\text { Cozzolino et al. (2012); Kovács et al. (2010); Oloruntoba (2010); } \\
\text { Maon et al.(2009); Yi and Ozdamar (2007) }\end{array}$ \\
\hline Agilidade e capacidade de resposta & McLachlin e Larson (2011); Kovács e Tatham (2009) \\
\hline Desafios na logística humanitária & Kovács e Spens (2011); Balcik et al. (2010) \\
\hline $\begin{array}{l}\text { Cooperação, coordenação } \\
\text { colaboração }\end{array}$ & $\begin{array}{l}\text { Akhtar et al. (2012); Heaslip et al. (2012); Jahre e Jensen (2010); } \\
\text { Chandes and Pache (2009); Perry (2007); Reitjens et al. (2007); Hicks } \\
\text { and Pappas (2006); }\end{array}$ \\
\hline Fundamentos em logística humanitária & Rutner et al., (2012); Tatham (2012); Jahre et al.(2009) \\
\hline Gestão de estoques & $\begin{array}{l}\text { Campbell e Jones (2011); Duran et al. (2011); Lodree (2011); Beamon } \\
\text { e Kotebla (2006) }\end{array}$ \\
\hline Fases em desastres & Altay e Green (2006) \\
\hline Processos, modelagem e desempenho & Adivar et al. (2010); Pourezzat et al. (2010); Beamon e Balcik (2008) \\
\hline Aquisições & $\begin{array}{l}\text { Ertem e Buyurgan (2011); Chang et al. (2010a,b) } \\
\text { Fonte: Healsip e Barber (2014) }\end{array}$
\end{tabular}

No contexto nacional, a revisão da literatura acadêmica brasileira sobre logística humanitária de BERTAZZO et al. (2013)identificou o artigo de BANDEIRA et al.(2011), o qual apresenta a atuação do Exército Brasileiro na operação de resposta ao desastre da região serrana fluminense em 2011. Os artigos de ROSA et al.(2014 e 2015) publicados após a revisão, também versam sobre o papel das Forças Armadas brasileiras em gestão de operações em desastres naturais com ênfase em logística humanitária.

A seguir são apresentados casos de atuação de militares em operações de resposta a desastres naturais identificados na literatura. Para a realização desta análise, buscaram-se, entre os artigos listados na Tabela 4, aqueles que analisavam casos de atuação militar neste tipo de operação, sendo identificados os trabalhos de Hicks e Pappas (2006), Olorutomba (2010) e Healsip e Barber (2014). Também foi realizada uma busca na base de dados ISI Web of Science e no Science Direct com a seguinte combinação de palavras-chave: [Military E Humanitarian E Disaster], resultando no levantamento de 64 artigos. Após a exclusão de artigos relacionados às áreas de política internacional e saúde, identificou-se que apenas três publicações traziam casos sobre a ação de militares em resposta a desastres (Telford e Grave, 2007; Weeks, 2007; Miller, 2012). Em muitos dos artigos, o termo "military" aparece apenas como um exemplo de ator da cadeia humanitária, sem de fato analisar a sua atuação na operação de resposta a desastre. 


\subsection{Casos de atuação de militares em Operações de Resposta a Desastres Naturais e Logística Humanitária encontrados na literatura acadêmica}

A força militar do país onde ocorreu o desastre costuma ser um dos primeiros atores a iniciarem a ajuda à população afetada (WEEKS, 2007 e HEASLIP et al., 2010). Segundo HEASLIP et al., (2012), os militares nacionais remetem equipes de emergência ao local, sob o controle operacional central do governo, exercido por uma agência civil, tal como ocorreu nos desastres recentes em Nova Orleans (2005), Samoa (2009) e Haiti (2010) e, onde o transporte militar foi utilizado para evacuar as vítimas e levar equipes da ajuda ao local afetado. $O$ apoio militar inicial garante uma resposta rápida de socorro às vítimas, até que a ajuda humanitária possa chegar ao local do desastre. No entanto, a percepção da população ou do governo local sobre os militares influencia diretamente a vontade de ONGs de trabalharem em conjunto com as FA. Em Bangladesh, por exemplo, a população local tinha uma visão positiva dos militares dos EUA, garantindo a colaboração com ONGs (DAVIDSON, HAYES e LANDON, 1996). Contudo, um dos principais desafios para os esforços humanitários no Afeganistão foi dissociar as atividades da comunidade humanitária e da coalizão militar liderada pelos EUA (VAN WASSENHOVE, 2006).

TELFORD e COSGRAVE (2007)analisaram a resposta internacional ao tsunami no Oceano Índico em 2004, concluindo que, mesmo com pouco planejamento conjunto e com a fraca coordenação entre os militares e os tradicionais atores humanitários, as FA desempenharam um papel fundamental na operação. Apesar do alto custo, os autores acreditam que os militares continuarão a desempenhar um papel importante na resposta a desastres internacionais.

A participação militar na operação de resposta ao terremoto no Paquistão em 2005 foi objeto de estudo de WEEKS (2007). O autor observou que, ao atuar em "operações de ajuda humanitária", as FA devem reduzir a burocracia, através da suspensão de alguns requisitos e procedimentos. HEASLIP e BARBER (2014) também destacam a necessidade de se criar novos processos mais descentralizados de modo a aumentar a flexibilidade e facilitar a atuação militar em operações de resposta a desastres. No caso do Paquistão (2005), uma grande quantidade de suprimentos humanitários foi movida com base em telefonemas e e-mails, algo que não aconteceria durante 0 curso das operações militares tradicionais. Este procedimento tem vantagens, mas também remove muitas salvaguardas para a eficiência. WEEKS (2007) também aponta a criação de um ponto centralizado de coleta temporária ou comissão central para filtrar informações como um elemento importante para o sucesso da operação no Paquistão.

HICKS e PAPPAS (2006) também realizaram pesquisas na coordenação dos atores na resposta ao terremoto do Paquistão ocorrido em 2005. Os autores observaram que, embora houvesse uma comissão central para coordenar as ações de socorro às vítimas, englobando os vários atores humanitários nacionais e internacionais presentes, a coordenação da tomada de decisões era fraca, limitada e de pouca objetividade. Em consequência, os militares tiveram que tomar a frente das decisões, por vezes indo de encontro às decisões políticas em prol da ajuda Revista Produção Online, Florianópolis, SC, v. 16, n. 3, p. 895-915, jul./set. 2016. 
humanitária na área das operações. O exemplo mais marcante foi à escolha da localização dos hospitais de campanha. A comissão central inicialmente locava as estruturas em áreas de pouca demanda ou subutilizava os meios em áreas já atendidas em saúde. Em função da necessidade proeminente das vítimas do terremoto, os militares tomaram para si a decisão da localização dos hospitais, equalizando o problema e decidindo de forma independente da comissão central. Para os autores, a multidisciplinaridade pessoal e material da força militar, aliada ao conhecimento da geopolítica e suas relações, inerentes a sua formação, foi decisiva no socorro às vítimas na área de desastre.

OLORUNTOBA (2010) descreve a operação de resposta ao ciclone Larry, ocorrido em 2006 na Austrália, considerada uma das mais eficazes na história do país. Neste caso, os militares trabalharam na busca e salvamento, evacuação, fornecimento de água potável, comida e abrigo, na limpeza de detritos que bloqueavam estradas e ameaçavam a população, bem como garantiram a segurança local. A fase de resposta da operação de ajuda humanitária foi realizada principalmente pela Força de Defesa Australiana, que também forneceu assistência médica, transporte e alimentação. $O$ autor afirma que as estratégias de resposta militar estavam em colaboração com outras agências civis do governo e ONGs, que gerenciaram o desastre da resposta inicial até a fase de reconstrução. Para o autor, o sucesso da operação deveu-se ao planejamento prévio, uma vez que os atores estavam conscientes de seus papéis e responsabilidades. Além disto, o autor defende o pré-posicionamento de unidades militares, suprimentos e recursos em prontidão de resposta em áreas propensas a desastres naturais, tal como acontece na Austrália. Essa solução contribui para reduzir o tempo de ciclo e aumentar a capacidade de resposta da cadeia de alívio.

No Brasil, BANDEIRA et al. (2011) analisaram a atuação das FA na resposta às chuvas na região serrana do Rio de Janeiro em 2011, tragédia que afetou 20 municípios e 90 mil pessoas. Os militares brasileiros executaram tarefas logísticas, como: distribuição de donativos, evacuação de feridos, tratamento e distribuição de água, desobstrução de vias, abastecimento de combustível. O Quadro de Engenheiros Militares do Exército Brasileiro também atuou no mapeamento da área imediatamente após o desastre, utilizando-se de tecnologia VANT - veículo aéreo não tripulado, com a finalidade de mostrar o melhor acesso às áreas que ainda estavam isoladas e facilitar o trabalho de resgate das vítimas.

MILLER (2012) aponta a tendência de militarização em operações de resposta a desastres como uma das consequências do furacão Katrina. Segundo o autor, a operação de resposta ao furacão Katrina teve a maior mobilização militar na história dos EUA, com a atuação de 63 mil militares, que foram chamados para controlar a situação, porque o sistema de gestão de desastres em todos os níveis estava sobrecarregado e mal equipado.

Ao analisar o envolvimento de forças militares em operações humanitárias do Conselho de Segurança da ONU, HEASLIP e BARBER (2014) observaram que as doutrinas militares adotadas no passado foram bastante distintas ao longo da última década. Assim, foi necessário que as FA incluíssem operações em ajuda humanitária Revista Produção Online, Florianópolis, SC, v. 16, n. 3, p. 895-915, jul./set. 2016. 
em suas doutrinas de emprego, com intuito de uniformizar sua atuação neste tipo de operação(RIETJENS, VOORDIJK eBOER, 2007 e HEASLIP et al., 2010). HEASLIP e BARBER (2014) ainda destacam a necessidade de um melhor entendimento entre os militares e os atores civis para se conseguir a colaboração entre estes stakeholders, sugerindo que isto só será possível por meio de iniciativas que estimulem a interação entres estes atores, seja por meio de treinamento ou ações conjuntas. Como exemplo, pode-se citar ação logística dos militares irlandeses no Haiti junto a WFP (World Food Program); o apoio do exército australiano aos socorristas da ONU nas missões humanitárias no Sudão e Somália; além de esforços para incentivar a participação de militares e civis em workshops e exercícios conjuntos. Os autores também apontam a necessidade de se criar uma linguagem e terminologia comum, que facilite a comunicação entre os atores civis e militares em operações humanitárias. Esta ação é fundamental para criar maior transparência, evitando equívocos e desconfiança entre as partes.

Em suma, a partir da análise dos casos relatados, conclui-se que pouco se é aproveitado em termos de conhecimento e experiência de uma operação para a outra. Muitas soluções são perdidas e acabam sendo reinventadas. Neste contexto, é preciso que seja criado um ambiente de aprendizagem contínua, analisando-se as melhores práticas e aproveitando-se desta experiência para o planejamento conjunto de operações futuras (HEASLIP e BARBER, 2014). Neste sentido, a Tabela 5 sintetiza as principais recomendações para maior eficiência da ação de militares em operações de resposta a desastres e logística humanitária encontradas na literatura.

Tabela 5: Recomendações da literatura para maior eficiência da ação militar em desastres e logística humanitária

\begin{tabular}{|c|c|c|}
\hline $\begin{array}{c}\text { Capacidade } \\
\text { Militar } \\
\end{array}$ & Recomend ações & Autores \\
\hline \multirow[t]{2}{*}{ Planejamento } & Planejamento prévio em conjunto com atores humanitários & $\begin{array}{l}\text { Telford e Cosgrave (2007) e } \\
\text { Oloruntoba (2010) }\end{array}$ \\
\hline & Aprendizagem contínua / lições aprendidas & Healsip e Barber (2014) \\
\hline \multirow{2}{*}{$\begin{array}{l}\text { Comando e } \\
\text { Controle }\end{array}$} & Atores conscientes de seus papéis e responsabilidades & Oloruntoba (2010) \\
\hline & $\begin{array}{l}\text { Criação de um ponto central de coleta temporária para } \\
\text { filtrar informações }\end{array}$ & Weeks (2007) \\
\hline \multirow[t]{2}{*}{ Logística } & $\begin{array}{l}\text { Redução da burocracia através da suspensão de alguns } \\
\text { requisitos e procedimentos }\end{array}$ & $\begin{array}{l}\text { Weeks (2007) e Healsip e } \\
\text { Barber (2014) }\end{array}$ \\
\hline & $\begin{array}{l}\text { Pré-posicionamento de unidades militares, suprimentos e } \\
\text { recursos em prontidão de resposta em áreas propensas a } \\
\text { desastres naturais }\end{array}$ & Oloruntoba (2010) \\
\hline $\begin{array}{l}\text { Operações e } \\
\text { Manobra }\end{array}$ & $\begin{array}{l}\text { Revisão dos processos e doutrinas para aumentar a } \\
\text { flexibilidade e facilitar sua atuação em operações de } \\
\text { resposta a desastres }\end{array}$ & Healsip e Barber (2014) \\
\hline \multirow[t]{2}{*}{ Comunicações } & Entendimento entre os militares e os atores civis & Healsip e Barber (2014) \\
\hline & Criação de uma linguagem e term inologia comum & Healsip e Barber (2014) \\
\hline
\end{tabular}

Na próxima seção, será abordada a atuação das Forças Armadas em operações de resposta a desastres no Brasil. 


\section{ATUAÇÃO DAS FORÇAS ARMADAS EM OPERAÇÕES DE RESPOSTA A DESASTRES NO BRASIL}

A Política Nacional de Defesa Brasileira (BRASIL, 2005) faz a previsão de emprego das FA nos seguintes casos: Situação de Guerra e Situação de Não Guerra. A Tabela 6 sintetiza as diferentes possibilidades de emprego das FA no Brasil.

Tabela 6: Emprego das FA

\begin{tabular}{llll}
\hline & Segurança e Defesa & Situação de Guerra & Defesa do País \\
\cline { 2 - 4 } $\begin{array}{l}\text { Emprego das } \\
\text { Forças }\end{array}$ & Atribuições Subsidiárias & Situação de Não Guerra & $\begin{array}{l}\text { Apoio a Defesa Civil } \\
\text { (emergências e catástrofes) }\end{array}$ \\
\cline { 2 - 4 } Armadas & Relações Internacionais & Guerra ou Não Guerra & \begin{tabular}{l} 
Compromissos internacionais \\
\cline { 3 - 4 }
\end{tabular} \\
\cline { 2 - 3 } & & & Operações de Paz \\
\hline
\end{tabular}

Fonte: Brasil (2005)

O manual de Doutrina Militar de Defesa (MINISTÉRIO DA DEFESA, 2007) prescreve que, além das ações relacionadas à Defesa da Pátria, à Garantia dos Poderes Constitucionais e à Garantia da Lei e da Ordem, ligadas diretamente à Segurança e à Defesa, as FA têm atribuições constitucionais relacionadas às atribuições subsidiárias, geralmente em situações de não guerra, de apoio à Defesa Civil (atendimento de emergências e catástrofes) e de Ajuda Humanitária; restabelecendo infraestruturas básicas e de governança, atendendo a compromissos internacionais e atuando contra delitos transnacionais e ambientais. $O$ foco deste trabalho é analisar o papel das FA nestas situações, mais especificamente no apoio a Defesa Civil em operações de resposta a emergências e catástrofes. Esta análise foi realizada com base no estudo de manuais e documentos das FA que tratam sobre o tema, além de entrevistas com três militares que atuam no planejamento de operações de resposta a desastres.

Segundo a Doutrina Militar Terrestre(EXÉRCITO, 2014a), a função das FA no Plano e Sistema Nacional de Proteção e Defesa Civil é apenas de cooperação e colaboração. A coordenação será sempre responsabilidade da Secretaria Nacional de Defesa Civil. As unidades militares poderão cooperar diretamente com as Comissões Estaduais e Municipais de Defesa Civil nas atividades de planejamento, prevenção e preparação dos estados e municípios, mediante prévia autorização do Comando de cada Força. As FA enviarão oficiais de ligação aos centros de coordenação e integração, denominado Centro de Operações de Defesa Civil, considerando as diversas especialidades necessárias à cooperação: Engenharia, Saúde, Aviação, Comando e Controle, Logística, dentre outras.

Entretanto, para que as FA possam ser empregadas, pode ser necessário a autorização e decretação por parte do Presidente da República, após o reconhecimento federal da situação de emergência ou estado de calamidade pública pela Secretaria Nacional de Proteção e Defesa Civil (BRASIL, 2012). Diante das diversas normas, estruturas e atores envolvidos, os autores deste artigo resumiram na Tabela 7 as fases/etapas/ações a realizar e o respectivo orgão responsável dentro do ciclo da gestão de desastres no país: 
Tabela 7: Funcionamento da gestão de desastres no Brasil

Fases / Etapas / Ações a realizar

Orgão Responsável

Alerta de desastre emitido pelo Centro Nacional de Monitoramento e de desastres Naturais (CEMADEN), vinculado ao Centro Nacional de Gerenciamento de Riscos e Desastres (CENAD)

Decretação da Situação de Emergência ou Estado de Calamidade Pública

Classificação da catástrofe conforme Codificação Brasileira de Desastres (COBRADE) e Cadastramento no Sistema Integrado de Informações sobre desastres (S2ID), no site do MI.

Reconhecimento Federal da Situação de Emergência ou Estado de Calamidade Pública pela Secretaria Nacional de Proteção e Defesa Civil.

Autorização e decretação do emprego das Forças Armadas nas atribuições subsidiárias de apoio a Defesa Civil

Diretrizes de emprego operacional das Forças Armadas conforme situação do desastre ou catástrofe - cooperação, pelo EMFA

Ativação do Plano de Contingência ao Desastre para ações de resposta conjunta pelo CENAD / MI, comunicando o Centro de Operações Conjuntas do Ministério da Defesa (COC/MD) e o Centro de Informação Estratégica de Vigilância e Saúde do Ministério da Saúde (CIEVS/MS)

Instalar um Centro de Monitoramento e Operações (Gabinete de crise) no cenário de Desastres, com controle operacional a cargo da Secretaria Nacional de Proteção e Defesa Civil

Requisitar, conforme a demanda, as ações de resposta, infraestrutura, pessoal e apoio logístico necessários ao MD e MS, sendo que a coordenação geral das atividades em campo será do Grupo de Apoio a Desastres (GADE) do MI.

Fonte: Elaborado pelos autores Ministério da Integração Nacional - MI Chefe do Poder Executivo do ente federativo

Orgão de Proteção e Defesa Civil do ente federativo

Ministério da Integração

Nacional - MI

Presidente da República

Ministério da Defesa - MD

MI coordenará as ações

\begin{tabular}{|c|c|}
\hline $\begin{array}{l}\text { Ministério } \quad \mathrm{da} \\
\text { Nacional, }\end{array}$ & Integração \\
\hline $\begin{array}{l}\text { Ministério } \\
\text { Nacional }\end{array}$ & Integração \\
\hline
\end{tabular}

Conforme o manual de logística(EXÉRCITO, 2014b), algumas das ações de apoio à Defesa Civil compreendem: apoio da Engenharia Militar em obras de infraestrutura do país, lançamento de pontes para o restabelecimento de tráfego; emprego de veículos terrestres, embarcações e aeronaves em operações de busca e salvamento, transporte de civis e evacuação de áreas em situações de emergência; distribuição de donativos; desobstrução de vias; atendimento médico; análise de imagens; e assistência religiosa. Estas ações estão associadas às principais capacidades operacionais das FA em operações de resposta a desastres, destacadas por Pettit e Beresford (2005), conforme a Tabela 3.

Observa-se que a gestão das operações de resposta a desastres no país tem evoluído. Houve um aumento expressivo nos gastos de governo na prevenção e mitigação nas catástrofes ocorridas no Brasil. Módulos compostos por pontes móveis, viaturas, embarcações, tratores, comunicação por satélite, ambulâncias, barracas hospitalares e hospitais de campanha foram adquiridos e distribuídos em postos estratégicos do país, a cargo do Ministério da Defesa. Centros de Estoque Estratégico para assistência humanitária foram criados para o abastecimento de todas as regiões do Brasil. A aquisição de kits compostos de: caminhonetes $4 \times 4$, tablet, GPS e rádio foram investidos nas defesas civis municipais, aparelhando as regiões e áreas de riscos propensas a ocorrer um desastre (MINISTÉRIO, 2014).

Verifica-se que, devido à definição do Protocolo de ações firmado entre o Ministério de Integração Nacional (MIN), Ministério da Defesa (MD) e Ministério da Saúde (MS), os atores envolvidos em operações de resposta a desastres no Brasil Revista Produção Online, Florianópolis, SC, v. 16, n. 3, p. 895-915, jul./set. 2016. 
estão mais cientes de seus papéis e responsabilidades, conforme recomendado por Oloruntoba (2010). A partir da definição dos papéis e da área de atuação fica mais fácil um planejamento conjunto, como sugerem Telford e Cosgrave (2007) e Oloruntoba (2010). Assim, após a ocorrência da catástrofe, é ativado o Plano de Contingência ao Desastre para ações de resposta conjunta.

Conforme recomendam Healsip e Barber (2014), as FA Brasileiras já estão atualizadas nas doutrinas bélicas internacionais em ajuda humanitária, cabendo ressaltar os recentes manuais de operações interagências (MINISTÉRIO DA DEFESA, 2013 e EXÉRCITO BRASILEIRO, 2014b), que orientam o preparo e emprego de forças militares no que tange à coordenação e cooperação com as agências governamentais, organizações intergovernamentais, não governamentais e do setor privado, tanto do país como no exterior.

Outro ponto positivo cabe aos Centros de Estoque Estratégico e equipamentos e módulos adquiridos, pré - posicionando de recursos e suprimentos prontos para uma resposta imediata, tal como recomendado por Oloruntoba (2010). Entretanto, apesar dos esforços do governo em abrir um canal de diálogo com todos os envolvidos, através das conferências organizadas pelos órgãos de proteção e defesa civil dos diversos entes federativos, o país ainda necessita criar uma terminologia comum entre os atores civis e militares, como sugerido por Healsip e Barber (2014). Isto facilitaria o entendimento entre os militares e os atores civis, questão também apontada pelos autores. Também merece destaque no cenário nacional a recomendação de Healsip e Barber (2014) sobre o desenvolvimento de um procedimento para levantamento das lições aprendidas, o que permitira um ciclo de aprendizagem contínua neste tipo de operação. Enfim, a Tabela 8 sintetiza a análise da ação de militares em operações de resposta a desastres no Brasil, tendo como base as principais recomendações apresentadas na Tabela 3. 
Tabela 8: Recomendações da literatura para maior eficiência da ação militar em desastres

\begin{tabular}{|c|c|c|}
\hline Capacidade & Recomendações & Cenário atual no Brasil \\
\hline \multirow[t]{2}{*}{ Planejamento } & Planejamento prévio em conjunto & $\begin{array}{l}\text { Após a ocorrência da catástrofe, MIN, MD e MS } \\
\text { ativam então plano de contingência ao desastre } \\
\text { para ações de resposta conjunta. }\end{array}$ \\
\hline & $\begin{array}{l}\text { Aprendizagem contínua / lições } \\
\text { aprendidas }\end{array}$ & $\begin{array}{l}\text { Este é um ponto de melhoria a ser implantado no } \\
\text { cenário nacional. }\end{array}$ \\
\hline \multirow[t]{2}{*}{$\begin{array}{l}\text { Comando } \\
\text { Controle }\end{array}$} & $\begin{array}{l}\text { Atores conscientes de seus papéis e } \\
\text { responsabilidades }\end{array}$ & $\begin{array}{l}\text { Os atores envolvidos estão mais cientes de seus } \\
\text { papéis e responsabilidades devido a definição do } \\
\text { Protocolo de ações firmados entre MIN, MD e MS. }\end{array}$ \\
\hline & $\begin{array}{l}\text { Criação de um ponto central de coleta } \\
\text { temporária para filtrar informações }\end{array}$ & $\begin{array}{l}\text { Sugere-se que seja estabelecida uma equipe no } \\
\text { centro de coordenação de operações de desastres, } \\
\text { responsável para coletar e filtrar informações. }\end{array}$ \\
\hline \multirow[t]{2}{*}{ Logística } & $\begin{array}{l}\text { Redução da burocracia através da } \\
\text { suspensão de alguns requisitos } \mathrm{e} \\
\text { procedimentos }\end{array}$ & $\begin{array}{l}\text { Este é um ponto de melhoria a ser implantado no } \\
\text { cenário nacional. }\end{array}$ \\
\hline & $\begin{array}{l}\text { Pré-posicionamento de unidades } \\
\text { militares, suprimentos e recursos em } \\
\text { prontidão de resposta em áreas } \\
\text { propensas a desastres }\end{array}$ & $\begin{array}{l}\text { Apesar de não haver um pré-posicionamento de } \\
\text { unidades militares, foram estabelecidos centros de } \\
\text { estoque estratégico para o abastecimento de todas } \\
\text { as regiões do Brasil. }\end{array}$ \\
\hline $\begin{array}{l}\text { Operações } \\
\text { Manobra }\end{array}$ & $\begin{array}{l}\text { Revisão dos processos e doutrinas de } \\
\text { modo a aumentar a flexibilidade e } \\
\text { facilitar sua atuação em operações de } \\
\text { resposta a desastres }\end{array}$ & $\begin{array}{l}\text { As FA estão atualizadas nas doutrinas bélicas } \\
\text { internacionais em ajuda humanitária, cabendo } \\
\text { ressaltar o recente Manual de Operações } \\
\text { Interagências. }\end{array}$ \\
\hline \multirow[t]{2}{*}{ Comunicações } & $\begin{array}{l}\text { Entendimento entre os militares e os } \\
\text { atores civis }\end{array}$ & $\begin{array}{l}\text { Há esforços do governo em abrir um canal de } \\
\text { diálogo com todos os envolvidos, através das } \\
\text { conferências organizadas pelos órgãos de proteção } \\
\text { e defesa civil dos diversos entes federativos. }\end{array}$ \\
\hline & $\begin{array}{l}\text { Criação de uma } \\
\text { terminologia comum }\end{array}$ & $\begin{array}{l}\text { O país ainda necessita criar uma terminologia } \\
\text { comum entre os atores civis e militares. }\end{array}$ \\
\hline
\end{tabular}

\section{CONSIDERAÇÕESFINAIS}

Verificou-se, no presente artigo, que a participação militar em operações de desastres não é algo novo e desempenha um importante papel nos esforços para aliviar o sofrimento humano e iniciar rapidamente a cadeia logística humanitária de serviços e materiais para o local afetado. Apesar de haver opiniões divergentes e controversas na sua utilização, o apoio militar, conjuntamente com as agências governamentais e não governamentais, fornece uma parceria positiva para este tipo de operação.

Em muitos dos ambientes operacionais ou espaço humanitário,a relação entre os atores humanitários e militares tem sido, difícil,complexa, desarticulada e não construtiva. Este trabalho sugere que esta falta de coordenação está ligada a uma série de fatores, incluindo as diferenças de terminologia, culturas e conceitos entre os atores. Contudo, percebe-se que um dos principais problemas é a diferença fundamental nas motivações, nos objetivos e nas abordagens dos atores em seus engajamentos na ação humanitária. Todavia, o artigo destaca os principais problemas para uma coordenação civil-militar mais eficaz, conforme Metcalfeet al. (2012), sugerindo ações de como melhorar o relacionamento e a coordenação entre atores militares e humanitários. 
Em particular, verifica-se que, quando a relação entre os atores tem sido mais positiva e proativa, há um resultado consistente de esforços de ambos os lados para desenvolver estruturas, regras e mecanismos claros de coordenação e liderança, desenvolvendo capacidades dedicadas em apoiar o processo de coordenação. Assim, pode-se concluir que é necessário um maior investimento, ao longo do tempo, para estabelecer eficazmente esta coordenação, explorando áreas de interesse comum, estabelecendo limites e aumentando o conhecimento mútuo e a compreensão entre os atores.

No relacionamento entre os atores onde existe objetivos comuns ou metas compartilhadas, documentação das experiências operacionais passadas, discutindose conjuntamente as melhores práticas e as lições aprendidas, esta interação contribui para o fortalecimento da coordenação humanitária civil-militar.Além disto, é necessária uma maior clareza sobre a forma de operacionalizar os principais aspectos do relacionamento civil-militar, incluindo o princípio do "último recurso", e também no que diz respeito aos protocolos de compartilhamento de informações.

São poucos os artigos acadêmicos que tratam da atuação de forças militares em operações de resposta a desastres e logística humanitária. Entretanto, foram identificados, na literatura internacional, diversos casos de sucesso do envolvimento das FA em operações de ajuda humanitária. No Brasil, a atuação das FA na Operação Serrana em 2011 constitui um exemplo de parceria entre governo, agências humanitárias e militares que traduzem uma interação harmônica e cooperativa para ajuda em desastres. Ainda em relação ao contexto brasileiro, as recomendações sugeridas neste artigo, com base na revisão da literatura, abrem o caminho do diálogo entre os atores. O Sistema Nacional de Proteção e Defesa do país está em fase de amadurecimento, mas verificamos a cooperação dos militares em assistir a Defesa Civil brasileira.

A forma de atuação e emprego das FA brasileiras e suas fases de operação em resposta a desastres naturais e logística humanitária foram apresentadas neste artigo. Por fim, a utilização das FA e seu papel na gestão de desastres e logística humanitária fornecem desafios e oportunidades para futuras discussões. $O$ envolvimento, cooperação e ajuda dos militares com as agências precisam ser refletidos, pesquisados e estudados, no intuito de demonstrar que o papel exercido pelos mesmos podem fornecer modelos aperfeiçoados de preparação, resposta imediata e reconstrução na gestão de desastres existentes na literatura a acadêmica.

\section{REFERÊNCIAS}

APTE, A. Humanitarian Logistics: A New Field of Research and Action. Foundations and Trends $\AA^{\circledR}$ in Technology, Information and Operations Management, v. 3, n. 1, p. 1-100, 2009. http://dx.doi.org/10.1561/0200000014

BANDEIRA, R. A. D. M.; CAMPOS, V. B. G.; BANDEIRA, A. D. P. F. Uma visão da logística de atendimento à população atingida por desastre natural. XXV Congresso de Pesquisa e Ensino em Transporte, p. 599-610, 2011.

BERTAZZO, T. R. et al. Revisão da literatura acadêmica brasileira sobre a gestão de operações em desastres naturais com ênfase em logística humanitáriaRevista

Revista Produção Online, Florianópolis, SC, v. 16, n. 3, p. 895-915, jul./set. 2016. 
Transportes, 2013.

BESSLER, M.; SEKI, K. Civil-Military Relations in Armed Conflicts: A Humanitarian Perspective, 2006.

BRASIL. Política de Defesa Nacional. 2005.

BRASIL. Política Nacional de Proteção e Defesa Civil - Lei 12.608. . 2012.

BURKLE, F. M. Anatomy of an ambush: security risks facing international humanitarian assistance. Disasters, v. 29, n. 1, p. 26-37, mar. 2005. http://dx.doi.org/10.1111/j.0361$\underline{3666.2005 .00272 . x}$

BYMAN, D. Uncertain partners: NGOs and the military. Survival, v. 43, n. 2, p. 97-114, 7 dez. 2010. http://dx.doi.org/10.1080/713660351

COLLINSON, S.; ELHAWARY, S.; MUGGAH, R. States of fragility: stabilisation and its implications for humanitarian action. Disasters, v. 34, n. SUPPL. 3, p. 275-296, 2010.

DAVIDSON, L. W.; HAYES, M. D.; LANDON, J. J. Humanitarian and Peace Operations: NGOs and the Military in the Interagency Process. n. December, p. 59, 1996.

DOD. Military Health Support for Stability Operations - Instruction NUMBER 6000.16Department of Defense, 2010.

EIDE, E. B. et al. Report on Integrated Missions 1. Independent Study for the Expanded UN ECHA Core Group, n. May, p. 1-52, 2005.

EXÉRCITO, B. Doutrina Militar Terrestre - EB20-MF-10.102, 2014a.

EXÉRCITO, B. Logística - EB20 - MC - 10.204BrasíliaExército Brasileiro, , 2014b.

HANLEY, C. J. Looking for lessons in Haiti's epic tragedy. The San Diego Union Tribune, 2010.

HARMER, A. Integrated Missions: A Threat to Humanitarian Security? International Peacekeeping, v. 15, n. 4, p. 528-539, 4 ago. 2008.

HEASLIP, G. et al. Performance measurement in humanitarian relief chains. European Journal of Operational Research, v. 2, n. 1, p. 290-305, 2010.

http://dx.doi.org/10.1108/JHLSCM-03-2013-0013

HEASLIP, G. et al. Developing supply chains in disaster relief operations through crosssector socially oriented collaborations: a theoretical model. Journal of Humanitarian Logistics and Supply Chain Management, v. 1, n. 1, p. 32-49, 2012.

HEASLIP, G.; BARBER, E. Using the military in disaster relief: systemising challenges and opportunities. Journal of Humanitarian Logistics and Supply Chain Management, v. 4, n. 1, p. 60-81, 2014.

HICKS, E. K.; PAPPAS, G. Coordinating Disaster Relief After the. v. 2, n. August, p. 4250, 2006.

HPG; ICRC. The Concept of Protection: towards a mutual understanding, 2011. 
IASC. Civil - Military Relationship in Complex Emergencies, 2004. Disponível em: $<$ http://www.refworld.org/cgi-bin/texis/vtx/rwmain?docid=4289ea8c4>

IASC. Civil-military coordination during humanitarian health actionGlobal Health Cluster, 2011.

IASC. IASC Non-Binding Guidelines on the use of Armed Escorts for Humanitarian Convoys, 2013.

JAHRE, M.; JENSEN, L.-M.; LISTOU, T. Theory development in humanitarian logistics: a framework and three cases. Management Research News, v. 32, n. 11, p. 1008-1023, 2009. http://dx.doi.org/10.1108/01409170910998255

KOVÁCS, G.; TATHAM, P. Responding To Disruptions in the Supply Network-From Dormant To Action. Journal of Business Logistics, v. 30, n. 2, p. 215-229, 2009.

http://dx.doi.org/10.1002/j.2158-1592.2009.tb00121.x

LILLY, D. Peacekeeping and the protection of civilians an issue for humanitarians ? Disponível em: <http://www.odihpn.org/humanitarian-exchange-magazine/issue48/peacekeeping-and-the-protection-of-civilians-an-issue-for-humanitarians>. Acesso em: 29 jun. 2015.

LIMA, F. S.; OLIVEIRA, D.; GONÇALVES, M. B. Formação de clusters para o gerenciamento da cadeia de suprimentos em operações humanitárias. Exacta - EP , São Paulo, v. 12, n. 1, p. 55-68, 2014. http://dx.doi.org/10.5585/exactaep.v12n1.4696

LIPNER, M.; HENLEY, L. Working better together: an perspective on improving australias's coordination in disaster responseinternational journal of pharmacy practice, 2010.

METCALFE, V.; GIFFEN, A.; ELHAWARY, S. UN Integration and Humanitarian Space: $\mathbf{n}$ Independent Study Integration Steering Group. HPG, n. December, 2011.

METCALFE, V.; HAYSOM, S.; GORDON, S. Trends and challenges in humanitarian civil - military coordination A review of the literature. [s.l: s.n.].

MILLER, L. M. Controlling disasters: recognising latent goals after Hurricane Katrina.

Disasters, v. 36, n. 1, p. 122-39, jan. 2012. http://dx.doi.org/10.1111/i.1467-

$\underline{7717.2011 .01244 . x}$

MINISTÉRIO, DA I. N. Prevenção de Desastres - Ações do governo federalAssessoria de Comunicação Social, , 2014. Disponível em: <www.mi.gov.br>

MINISTÉRIO DA DEFESA, B. Doutrina Militar de Defesa - MD51-M-04, 2007.

NATARAJARATHINAM, M.; CAPAR, I.; NARAYANAN, A. Managing supply chains in times of crisis: a review of literature and insights. International Journal of Physical Distribution \& Logistics Management, v. 39, n. 7, p. 535-573, 2009.

http://dx.doi.org/10.1108/09600030910996251

NMCG et al. NGO-Military Contact Group Conference 2011 CIVIL-MILITARY

RELATIONS IN NATURAL DISASTERS : New Developments from the FieldJointly hosted by the British Red Cross and the Foreign \& Commonwealth Office. Anais...2011Disponível em: <http://reliefweb.int/sites/reliefweb.int/files/resources/Full_Report_3072.pdf>

O'CALLAGHAN, S.; PANTULIANO, S. Protective action : Incorporating civilian protection into Revista Produção Online, Florianópolis, SC, v. 16, n. 3, p. 895-915, jul./set. 2016. 
humanitarian response. Humanitarian Policy Group Report, v. 26, n. December, p. 64, 2007.

OCHA. Directrices sobre el uso de recursos militares y de la defensa civil extranjeros en operaciones de socorro en casos de desastre - Diretrizes de Oslo, 2007.

OCHA. Civil-Military Guidelines \& Reference for Complex Emergencies. Nova York: Office for the Coordination of Humanitarian Affairs, 2008a. v. 1234

$\mathrm{OCHA}$. Directrices y referencias civiles y militares para situaciones de emergencia complejas. Espanhol ed. Nova York: Naciones Unidas, 2008b.

$\mathrm{OCHA}$. Meeting of the Consultative Group on the Use of Military and Civil Defence Assets (MCDA) 2011. Geneva: [s.n.].

OLORUNTOBA, R. An analysis of the Cyclone Larry emergency relief chain: Some key success factors. International Journal of Production Economics, v. 126, n. 1, p. 85-101, 2010. http://dx.doi.org/10.1016/j.ijpe.2009.10.013

ONU. Decisions 2011/20 ONU, 2011.

PETTIT, S. J.; BERESFORD, A. K. C. Emergency relief logistics: an evaluation of military, non-military and composite response models. International Journal of Logistics, v. 8, n. December, p. 313-331, 2005. http://dx.doi.org/10.1080/13675560500407325

PROJECT, T. S. The Sphere Project - Humanitarian Charter and Minimum Standards in Humanitarian Response. v. 1. Disponível em:< http://www.spherehandbook.org/> acesso em 08/08/2016.

PUGH, M. Military intervention and humanitarian action: trends and issues. Disasters, v. 22, n. 4, p. 339-351, 1998. http://dx.doi.org/10.1111/1467-7717.00097

RANA, R.; REBER, F. Discussion Paper CIV MILComissão Europeia, 2007

RIETJENS, S. J. H. et al. Inter-organisational communication in civil - military cooperation during complex. Disasters, v. 33, n. 3, p. 412-435, 2009. http://dx.doi.org/10.1111/j.1467$\underline{7717.2008 .01081 . x}$

RIETJENS, S. J. H.; VOORDIJK, H.; BOER, S. J. DE. Co-ordinating humanitarian operations in peace support missions. Disaster Prevention and Management, v. 16, n. 1, p. 56-69, 2007. http://dx.doi.org/10.1108/09653560710729811

ROSA, P. R. S. DA; BANDEIRA, R. A. DE M.; LEIRAS, A. O papel das forças armadas brasileiras em gestão de operações em desastres naturais com ênfase em logística humanitária. Curitiba - PRXXVIII Congresso de Pesquisa e Ensino em Transporte, 2014.

SCHR. Position Paper on Humanitarian- Military RelationsSteering Committee for Humanitarian Response, 2010.

TELFORD, J.; COSGRAVE, J. The international humanitarian system and the 2004 Indian Ocean earthquake and tsunamis. Disasters, v. 31, n. 1, p. 1-28, mar. 2007. http://dx.doi.org/10.1111/j.1467-7717.2007.00337.x

THOMPSON, W. C. Success in Kashmir: a positive trend in civil-military integration during humanitarian assistance operations. Disasters, v. 34, n. 1, p. 1-15, jan. 2010. 
http://dx.doi.org/10.1111/j.1467-7717.2009.01111.x

UNCH. UNHCR and the military - A Field GuideGeneva, 2006. Disponível em: <http://www.refworld.org/docid/465702372.html>

VAN WASSENHOVE, L. N. Humanitarian aid logistics: supply chain management in high geart. Journal of the Operational Research Society, v. 57, n. 5, p. 475-489, 2006. http://dx.doi.org/10.1057/palgrave.jors.2602125

WEEKS, M. R. Organizing for disaster: Lessons from the military. Business Horizons, v. 50, n. 6, p. 479-489, 2007. http://dx.doi.org/10.1016/i.bushor.2007.07.003

WEISS, T. G. A research note about military-civilian humanitarianism: more questions than answers. Disasters, v. 21, n. 2, p. 95-117, 1997. http://dx.doi.org/10.1111/1467-7717.00048

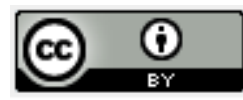

Artigo recebido em 09/09/2015 e aceito para publicação em 04/08/2016

DOI: http://dx.doi.org/ 10.14488/1676-1901.v16i3.2162 